\title{
Phytochemical Constituents and Pharmacological Effects of Licorice: A Review
}

\author{
Nazim A. Mamedov and Dilfuza Egamberdieva
}

\section{Introduction}

Licorice is one of the most widely used and extensively researched medicinal plants of the world (Hoffman 2000; Öztürk et al. 2017). The word liquorice essentially derives from Old Greek glykyrrhiza, glykys means "sweet," and rhiza is "root" (Schulz et al. 1998). One of the main active ingredients is glycyrrhizin, which has a cortisone-like effect. Glycyrrhizin is also 50 times sweeter than sucrose (Brown 1995). Liquorice has several names such as sweetwood, licorice, liquorice radix, reglisse (French), lakritzeholz (German), Gan Cao (Chinese), Meyan or Beyan (Turkish), and Solodka (Russian) (Mills and Bone 2000). Licorice roots have been used worldwide as a medicine and flavor in industry for over 4000 years. Medicinal uses of licorice are recorded in texts such as Assyrian Herbal (2000 BC) and Ebers Papyrus (1600 BC) (Lucas 1976; Reid 2001). Licorice is believed to have originated in Iraq. The most widely distributed species Glycyrrhiza glabra is found in Spain, Italy, Turkey, the Caucasus, Central Asia, and the western part of China whereas Glycyrrhiza uralensis is distributed form Central Asia to Mongolia and China (Hayash et al. 2003). Various species of licorice are currently grown on commercial scale in Spain, Italy, France, Greece, India, Iran, Iraq, Turkey, Turkmenistan, Uzbekistan, Syria, Afghanistan, Azerbaijan, China, and to a limited extent in England and the United States (Sokolov and Zamotayev 1985; Chevallier 1996).

\footnotetext{
N. A. Mamedov ( ()

Medicinal Plants Program, Stockbridge School of Agriculture, University of Massachusetts at Amherst, Amherst, MA, USA

e-mail: mamedov@cas.umass.edu

D. Egamberdieva

Faculty of Biology and Soil Sciences, National University of Uzbekistan,

Tashkent, Uzbekistan
} 


\section{Taxonomic Description}

The genus Glycyrrhiza is in the family Leguminosae and about 30 species are accepted up to today including G. aspera, G. bucharica, G. echinata, G. eurycarpa, G. glabra, G. iconica, G. inflata, G. korshinskyi, G. lepidota, G. macedonica, G. pallidiflora, G. squamulosa, G. triphylla, G. uralensis, and G. yunnanensis (Nomura et al. 2002; Fiore et al. 2005).

\section{Botanical Description}

Licorice is a perennial herb which grows $1-2 \mathrm{~m}$ tall. The plant has a long cylindrical burrowing rootstock that grows to a depth for $1 \mathrm{~m}$. Horizontal stolons grow outwards and typically reach $1.5-1.8 \mathrm{~m}$ in length, although they may grow to a length of $7 \mathrm{~m}$. The bark on licorice root is dark reddish, while the inside of the roots is bright yellow. Leaves are alternate, pinnate, with 9-17 ovate, yellow-green leaflets, each $2.5-5 \mathrm{~cm}$ long. The spikes of pealike flowers may be white, purple, or yellow. Spikes are usually $10-15 \mathrm{~cm}$ long and are born from leaf axils. Seedpods are maroon, $3 \mathrm{~cm}$ long, oblong, pointed, and flattened. Licorice roots are harvested 3-4 years after planting (Huxley 1992; Weiss and Fintelmann 2000).

\section{Traditional Uses}

Ancient Egyptians, Greeks, and Romans recognized the benefits of licorice in treating coughs, colds, and chills. In the days of Hippocrates, licorice was prescribed for dropsy because of thirst-quenching properties of licorice drugs (Biondi et al. 2005). The use of licorice for stomach and intestinal ulcers goes back at least to the Greek physician Dioscorides in first century AD, although modern clinical use began in about 1930. The ancient Hindus used licorice for improving sexual vigor, and Chinese for strength and endurance and they prepared it most often in tea (Davis and Morris 1991).

In traditional medicine licorice roots have been used against treating chest and lung diseases, pneumonia, bronchitis, arthritis, bronchial asthma, kidney diseases, heart diseases, gastric ulcer, mouth ulcers, coughs, swellings, excessive salivation, fluid retention, low blood pressure, allergies, catarrhs of the upper respiratory tract, liver toxicity, hyperglycemia, Addison's disease, pancreatic disorders, flatulence, sexual debility, skin diseases, leukorrhea, hoarseness, and certain viral infections (Blumenthal et al. 2000; Anon 2005; Armanini et al. 2002; Sharma et al. 2013). Current pharmacopoeias from France, Germany, and Britain are in general agreement on the medicinal application of licorice. In Indian medicine, licorice is used for treatment of influenza, eye diseases, uterine complaints, biliousness, liver 
disease, and arthritis (Saxena 2005). In Chinese medicine, licorice is used to treat acne and pimples, nervous disorders such as hysteria, irritability, and epilepsy as well as reduce the toxic or drastic action of other herbs, and to harmonize herbal formulas (Zhu 1998). In earlier studies Kong et al. (1984) showed that root extract of licorice was used to treat diarrhea in mice, whereas Hong et al. (1988) demonstrated strong diuretic activity of licorice in rats. Extract of G. glabra was used to treat emotional irritability in adults (Tsuda et al. 1986) and stress (Shirinyan et al. 1988). Licorice extract was also used to treat eczema (Sheehan and Atherton 1992), and allergic dermatitis (Sokolov and Zamotayev 1985).

\section{Pharmacological Activities}

Pharmacological studies have confirmed that Glycyrrhiza species exhibit a broad range of biological activities. In Table 1 various pharmacological activities of Glycyrrhiza species are presented. Many pharmacological activities, such as hypocholesterolemic and hypoglycemic (Sitohy et al. 1991), anxiolytic (Ambawade et al. 2001), antimicrobial (Patil et al. 2009), antiviral (Cinati et al. 2003), preliminary free radical scavenging (Toshio et al. 2003), anti-ulcer (Da Nagao et al. 1996), cytotoxic, antitumor (Hossain et al. 2004), antiallergic (Ram et al. 2006; Kroes et al. 1997), antidiabetic (Isbrucker and Burdock 2006), anticarcinogenic (Satomi et al. 2005), antioxidant (Vaya et al. 1998), anti-inflammatory (Kakegawa et al. 1992; Fujisawa et al. 2000), and hepatoprotective activities (Van Rossum et al. 2001; Wu et al. 2006); skin eruptions; dermatitis; and eczema (Akhtar et al. 2011), have been reported for roots of Glycyrrhiza species. The licorice can also be used in the management of impaired learning, dementia, Alzheimer's disease, and other neurodegenerative disorders (Chakravarthi et al. 2012).

\section{Antimicrobial Activity}

The antimicrobial activity of plant oils and extracts has been recognized for many years and indicated that it may be attributed to alkaloids, saponins, flavonoids, tannin, glycosides, and phenols (Shinwari et al. 2009). Patil et al. (2009) observed antimicrobial activity of ethanolic extract of G. glabra against Bacillus subtilis MTCC (121), Staphylococcus aureus MTCC (96), Pseudomonas aeruginosa MTCC (429), Escherichia coli MTCC (443), and one fungal strain Candida albicans. Candida albicans and Trichophyton rubrum growth was also inhibited by ethanolic extracts of G. glabra and their fractions (Meghashri 2009), whereas methanolic extracts of G. glabra had more fungicidal effect against Arthrinium sacchari and Chaetomium funicola (Hojo and Sato 2002). In another study Tharkar et al. (2010) also observed antifungal activity of G. glabra extracts. In the following study Gupta et al. (2008) reported antimicrobial activity of G. glabra against 
Table 1. Pharmacological activities of licorice

\begin{tabular}{|c|c|c|}
\hline Species & $\begin{array}{l}\text { Pharmacological } \\
\text { activity }\end{array}$ & References \\
\hline $\begin{array}{l}\text { G. glabra } \\
\text { G. uralensis }\end{array}$ & Antimicrobial & $\begin{array}{l}\text { Hatano et al. (2000), Tanaka et al. (2001), Hojo and Sato } \\
\text { (2002), Fukai et al. (2002), Nerya et al. (2003), Statti } \\
\text { et al. (2004), Gupta et al. (2008), Fatima et al. (2009), } \\
\text { Shinwari et al. (2009), Patil et al. (2009), Nitalikar et al. } \\
\text { (2010), Tharkar et al. (2010), Meghashri (2009), Nand } \\
\text { et al. (2012), Varsha et al. (2013), Ali (2013) }\end{array}$ \\
\hline \multirow[t]{3}{*}{$\begin{array}{l}\text { G. glabra } \\
\text { G. uralensis }\end{array}$} & Antiviral & $\begin{array}{l}\text { Hattori et al. (1989), Crance et al. (1990), Plyasunova } \\
\text { et al. (1992), Van Rossum et al. (1999), Wang et al. } \\
\text { (2000), Tandon et al. (2002), Crance et al. (2003), Chen } \\
\text { et al. (2004), Orlent et al. (2006), Pellatti et al. (2009), } \\
\text { Fiore et al. (2009), Kuo et al. (2009) }\end{array}$ \\
\hline & Anti-inflammatory & $\begin{array}{l}\text { Matsui et al. (2004), Shin et al. (2008), Vibha et al. } \\
\text { (2009), Tokiwa et al. (2004), Furuhashi et al. (2005), } \\
\text { Kang et al. (2005) }\end{array}$ \\
\hline & Anti-ulcer & $\begin{array}{l}\text { Bennett et al. (1980), Van Marle et al. (1981), Da Nagao } \\
\text { et al. (1996), Masoomeh and Kiarash (2007), Adel et al. } \\
\text { (2005) }\end{array}$ \\
\hline \multirow[t]{5}{*}{$\begin{array}{l}\text { G. inflate } \\
\text { G. glabra } \\
\text { G. uralensis }\end{array}$} & Antitumor & $\begin{array}{l}\text { Kakegawa et al. (1992), Fukai et al. (1998), Shiota et al. } \\
\text { (1999), Liu et al. (1998), Tamir et al. (2000), Nomura } \\
\text { et al. (2002), Salvi et al. (2003), Kanazawa et al. (2003), } \\
\text { Hsu et al. (2004), Hossain et al. (2004), Jo et al. (2005), } \\
\text { Sheela et al. (2006), Yoon et al. (2005), Dong et al. } \\
\text { (2007), Rahman and Rashid (2008) }\end{array}$ \\
\hline & Antioxidant & $\begin{array}{l}\text { Vaya et al. (1997), Hesham and Shgeru (2002), } \\
\text { Muralidharan et al. (2009), Singh (2010), Siracusa et al. } \\
\text { (2011), Škrovánková et al. (2012), Lateef et al. (2012), } \\
\text { Ali (2013) }\end{array}$ \\
\hline & $\begin{array}{l}\text { Hepatoprotective } \\
\text { activity }\end{array}$ & $\begin{array}{l}\text { Subramoniam and Pushpangadan (1999), Van Rossum } \\
\text { et al. (2001), Jeong et al. (2002), Curreli et al. (2007), } \\
\text { Al-Razzuqi et al. (2012) }\end{array}$ \\
\hline & Dermatological effect & Lee et al. (1997), Lee et al. (2005), Akhtar et al. (2011) \\
\hline & $\begin{array}{l}\text { Antidepressant and } \\
\text { memory-enhancing } \\
\text { activity }\end{array}$ & $\begin{array}{l}\text { Gareri et al. (2004), Dhingra and Sharma }(2005,2006) \text {, } \\
\text { Zhao et al. (2006), Wang et al. (2008), Chakravarthi et al. } \\
\text { (2012) }\end{array}$ \\
\hline
\end{tabular}

Mycobacterium tuberculosis. The ethanol, chloroform, and acetone extracts of licorice showed antibacterial activity against Bacillus subtilis, Staphylococcus aureus, Escherichia coli, and Pseudomonas aeruginosa (Nitalikar et al. 2010). G. glabra extracts showed high antibacterial activity against Staphylococcus epidermidis, Staphylococcus aureus, and Propionibacterium acnes (Nand et al. 2012). Varsha et al. (2013) presented the antibacterial effect of G. glabra extract against Pseudomonas aeruginosa, Shigella flexneri, Escherichia coli, Staphylococcus epidermidis, S. aureus, and Bacillus subtilis. The methanolic extract of G. glabra showed antimicrobial activity against various strains of Staphylococcus aureus ATCC 29213, Enterococcus faecalis ATCC 29212, Micrococcus luteus ATCC 9622, Proteus mirabilis ATCC 29852, Proteus vulgaris ATCC 6361, and Escherichia coli 
ATCC 4350 (Statti et al. 2004). Shinwari et al. (2009) observed antibacterial activity of G. glabra extracts against Pseudomonas aeruginosa and B. subtilis.

The antibacterial activity of secondary metabolites obtained from Glycyrrhiza species against upper airway respiratory tract bacteria such as Streptococcus pyogenes, Haemophilus influenza, and Moraxella catarrhalis was studied by Tanaka et al. (2001). The authors observed that licoricidin and coumarin derivatives such as glycyrol, glycyrin, and glycycoumarin exhibited high activity against all tested microorganisms. The compound glabridin, derived from root of G. glabra, was found to be active against both yeast and filamentous fungi (Fatima et al. 2009). Glabridin showed various biological activities such as antimicrobial activity against Helicobacter pylori (Fukai et al. 2002), Staphylococcus aureus (Hatano et al. 2000), and inflammation (Nerya et al. 2003). Essential oils derived from G. glabra showed inhibitory effect against Aspergillus flavus (Ali 2013).

\section{Antiviral Activity}

Licorice and glycyrrhizate compounds have long been used as a potential therapeutic agent for several virus diseases including chronic hepatitis B and C, as well as human acquired immunodeficiency syndrome (AIDS) (Wang et al. 2000; Chen et al. 2004; Orlent et al. 2006; Tandon et al. 2002). There are other several reports indicating antiviral activity of glycyrrhizin and glycyrrhizic acid, where the compounds inhibited growth and cytopathology of hepatitis A and C (Crance et al. 1990: Van Rossum et al. 1999), and immunodeficiency virus (HIV) (Hattori et al. 1989; Plyasunova et al. 1992). Fiore et al. (2009) observed that glycyrrhizin and its derivatives from Glycyrrhiza glabra reduced hepatocellular damage in chronic hepatitis B and $\mathrm{C}$ and they also showed antiviral activity against HIV-1, SARS-related coronavirus, respiratory syncytial virus, arboviruses, vaccinia virus, and vesicular stomatitis virus.

According to Crance et al. (2003) glycyrrhizin has antiviral effect, through an inhibition of viral particle to cell membrane binding, or through cellular signal transduction mechanisms. 18 $\beta$-Glycyrrhetinic acid was found to be a promising biological alternative for the topical treatment of persistent vulvovaginal candidiasis (Pellatti et al. 2009). In another study Cinati et al. (2003) observed in vitro antiviral effects for viruses causing respiratory tract infections like influenza virus and the severe acute respiratory syndrome (SARS) corona virus, and human immunodeficiency virus (HIV).

Kuo et al. (2009) studied the potential use of G. uralensis for treatment of human infection by enterovirus type 71 (EV71) which can cause life-threatening meningoencephalitis. 


\section{Anti-inflammatory}

The species of Glycyrrhiza has also been used to treat allergies and other inflammatory diseases (Matsui et al. 2004). Shin et al. (2008) studied anti-inflammatory effects of glycyrol (benzofuran coumarin) isolated from G. uralensis and found that glycyrols have potential anti-inflammatory effect. In another study Vibha et al. (2009) reported steroid-like anti-inflammatory activity of constituents derived from licorice root, similar to the action of hydrocortisone. They explained this finding due to inhibition of phospholipase A2 activity, an enzyme critical to numerous inflammatory processes.

Matsui et al. (2004) reported that glycyrrhetinic acid (ED 50, $200 \mathrm{mg} / \mathrm{kg}$ ) showed an inhibitory effect on carrageenan-induced rat paw edema and antiallergic activity. The secondary metabolites of G. glabra, namely glycyrrhizic acid, glabridin, and licochalcone A, showed an anti-inflammatory effect (Tokiwa et al. 2004; Furuhashi et al. 2005; Kang et al. 2005).

\section{Anti-ulcer}

In earlier work Bennett et al. (1980) demonstrated the anti-ulcer activity of deglycyrrhizinated licorice formulations using a rat model of aspirin-induced gastric mucosal damage. It has been found that the formulation promotes healing by increasing mucus production and blood supply to the damaged stomach mucosa, thereby enhancing mucosal healing (Van Marle et al. 1981; Da Nagao et al. 1996). Masoomeh and Kiarash (2007) reported anti-ulcerogenic effect of carbenoxolone derived from the root of licorice by inhibiting the secretion of gastrin. It has been explained by raising the concentration of prostaglandins in the digestive system by licorice compound that promote mucus secretion from the stomach. Adel et al. (2005) reported on the anti-pepsin effect of secondary metabolites of licorice which prolongs the life span of surface cells in the stomach.

\section{Antitumor}

The phytochemical constituents of licorice are reported to demonstrate anticancer effects in in vivo and in vitro studies (Salvi et al. 2003). For example they inhibit tumor formation and growth in breast (Tamir et al. 2000), liver (Shiota et al. 1999), and skin cancer (Liu et al. 1998). In earlier studies Fukai et al. (1998) reported the inhibitory activity of phenolic compounds such as isoliquiritigenin, semilicoisoflavone B, gancaonin $\mathrm{C}$ licoisoflavone $\mathrm{B}$, and licoisoflavanone for the growth of both B. subtilis H17 (wild type) and M45 (recombinationless mutant cells). In another study Sheela et al. (2006) observed that the extract of G. glabra inhibited 
proliferation of tumor cells and inhibited angiogenesis in in vivo assay. Jo et al. (2005) observed that the ethanol extract of G. uralensis root induced apoptosis and G1 cell cycle arrest in MCF-7 human breast cancer cells. The ethanolic extract and glycyrrhizin display antiproliferative effects against the MCF-7 in a dose-dependent manner (Dong et al. 2007). Similar results were observed by Jo et al. (2005) where the ethanol extract of $G$. uralensis root induced apoptosis and G1 cell cycle arrest in MCF-7 human breast cancer cells. Yoon et al. (2005) found that licochalcone E from the roots of $G$. inflate exhibited the most potent cytotoxic effect compared with the known antitumor agents, licochalcone $\mathrm{A}$ and isoliquiritigenin. In the studies of Nomura et al. (2002) several compounds derived from G. glabra, namely glyasperin A, gancaonin $\mathrm{P}$, licochalcone $\mathrm{B}$, topazolin, and gancaonin $\mathrm{O}$, showed relatively higher cytotoxic activity against human oral squamous carcinoma cell line HSC-2. In the following studies Yoon et al. (2005) showed that licochalcone E, a new retrochalcone derived from the G. inflata, exhibited the potent cytotoxic effect. Hsu et al. (2004) reported that isoliquiritigenin inhibited proliferation of the human non-small cell lung cancer A549 cell line, inducing apoptosis and locking cell cycle progression in the G1 phase. Similar results were observed by Kanazawa et al. (2003) where isoliquiritigenin inhibited the growth of prostate cancer and suggested the compound as a cancer chemopreventive agent in humans. The results indicate that biologically active compound in the root of licorice might be very useful as antiproliferative and antitumor agents (Rahman and Rashid 2008; Hossain et al. 2004).

\section{Antioxidant}

It has been reported that the extract of G. glabra leaves has been proved to have antioxidant, anti-genotoxic, and anti-inflammatory activities (Siracusa et al. 2011). Several phytochemical constituents derived from Glycyrrhiza roots are considered as a potential source of antioxidants (Singh 2010; Lateef et al. 2012). For example in earlier studies Vaya et al. (1997) reported about significant antioxidant activity of isoflavones glabridin and hispaglabridins A and B. Hesham and Shgeru (2002) have reported that flavonoids like luteolin, rutin, and apigenin derived from the root of $G$. glabra possess antioxidant properties. In the following study phenolic compounds have been reported as the main compound linked to antioxidant activity (Škrovánková et al. 2012).

Muralidharan et al. (2009) have found that the ethanol extract of G. glabra possesses a cerebroprotective effect in hypoxic rats, which may be mediated by its antioxidant effects. Essential oil of G. glabra exhibited DPPH radical scavenging activity (85.2\%) at a dose of $400 \mu \mathrm{g} / \mathrm{mL}$ (Ali 2013), whereas methanolic extract exhibited 91.3\% scavenging activity at a dose of $62.5 \mu \mathrm{g}$ (Lateef et al. 2012). Franceschelli et al. (2011) observed that licochalcone $\mathrm{C}$ has antioxidant properties since it reduces the production of superoxide radicals and consequently reduces the activity of inducible nitric oxide synthase (iNOS). 


\section{Hepatoprotective Activity}

In traditional medicine G. glabra were used to treat various liver diseases (Subramoniam and Pushpangadan 1999). Later modern medicinal studies showed that secondary metabolites derived from licorice were found to lower serum liver enzyme levels and improve tissue pathology in hepatitis patients (Van Rossum et al. 2001).

Glycyrrhizic acid induced a significant reduction in serum aminotransferases and improved the liver histology (Curreli et al. 2007). In recent studies Al-Razzuqi et al. (2012) demonstrated that the aqueous extract of G. glabra showed a significant effect in ameliorating liver functions in acute liver diseases when it was given in a single dose per day of $2 \mathrm{mg} / \mathrm{kg}$ body weight. In another study the protective effects of glycyrrhetinic acid against the carbon tetrachloride-induced hepatotoxicity and retrorsine-induced liver damage were reported (Jeong et al. 2002).

\section{Dermatological Effect}

The bioactive compounds derived from Glycyrrhiza roots have also showed skinwhitening, depigmenting, antiaging, anti-acne, and anti-erythemic properties (Lee et al. 1997). In recent studies Akhtar et al. (2011) found significant decrease in skin melanin by formulation of G. glabra extracts. Lee et al. (2005) explained that glycyrrhizin derived from the root of G. glabra induced melanin formation that may be mediated via the activation of a tyrosinase gene expression.

\section{Antidepressant and Memory-Enhancing Activity}

Licorice has also been found to have a memory-enhancing activity in passive avoidance paradigm (Dhingra and Sharma 2005) and antidepressant-like activity in mouse immobility tests (Dhingra and Sharma 2006). Several secondary metabolites derived from G. uralensis, e.g., liquiritin, demonstrated an antidepressant effect on chronic stress-depressed rats (Zhao et al. 2006). In the following studies Wang et al. (2008) also reported antidepressant-like activity of liquiritin and isoliquiritin in two classic animal behavior despair tests - the Forced Swimming Test (FST) and the Tail Suspension Test (TST) in mice. The authors explained the mechanism of action of those compounds which may be due to increased 5-hydroxytryptamine and norepinephrine in the mouse hippocampus, hypothalamus, and cortex. The other compound carbenoxolone also found in licorice demonstrated sedative and muscle-relaxant activities in mice and in genetically epilepsy-prone rats (GEPRs) (Gareri et al. 2004).

Chakravarthi et al. (2012) studied the impact of root extract of G. glabra on learning and memory in 1-month-old male Wistar albino rats and they found that 
150 and $225 \mathrm{mg} / \mathrm{kg}$ doses have shown a significant enhancement in learning and memory which is comparable to control. They explained that such improvement is due to antioxidant and anti-inflammatory action of plant extract where susceptible brain cells get exposed to less oxidative stress resulting in reduced brain damage and improved neuronal function.

\section{Other Effects}

There are also many studies reporting on the various pharmacological activities of licorice extract and biologically active compounds. For example the secondary metabolites liquiritigenin and isoliquiritigenin derived from the root of G. glabra showed dose-related antiallergic activities (Kakegawa et al. 1992).

Mishra et al. (2011) evaluated the anti-arthritic activity of G. glabra by significant reduction of paw edema volume and its capacity to stabilize lysosomal enzyme activity such as ACP significantly. The results justified the benefit of G. glabra in the treatment of inflammation-associated diseases like arthritis. Asgary et al. (2007) investigated the effect of G. glabra extract on blood lipids and atherosclerosis in rabbits fed with high-cholesterol diet. The authors found that G. glabra extract significantly decreased total cholesterol (TC), low-density lipoprotein cholesterol (LDL-C), and triglyceride (TG) levels and increased high-density lipoprotein cholesterol (HDL-C) and lessened atherosclerotic lesion in aorta. Similar results were observed by Fuhrman et al. (2002) where G. glabra extract decreased TC, TG, and LDL cholesterol and increased HDL cholesterol in hypercholesterolemic patients. Won et al. (2007) reported the use of licorice as food ingredients for obesity. They observed that licochalcone A derived from $G$. uralensis reduced the lipase activity as a new inhibitor of pancreatic lipase.

\section{Phytochemistry}

Biologically active compounds are primarily secondary metabolites and their derivatives such as alkaloids (Sarker and Nahar 2007; Varsha et al. 2013), glycosides (Firn 2010), flavonoids (Kar 2007; Varsha et al. 2013), phenolics (Cai et al. 2004; Puupponen-Pimiä et al. 2001), saponins (Sarker and Nahar 2007; Vashist and Sharma 2013), tannins (Kar 2007; Varsha et al. 2013), terpenes (Martinez et al. 2008), anthraquinones (Maurya et al. 2008; Vashist and Sharma 2013), essential oils (Martinez et al. 2008; Vashist and Sharma 2013), and steroids (Madziga et al. 2010; Varsha et al. 2013).

Licorice extract contains sugars, starch, bitters, resins, essential oils, tannins, inorganic salts, and low levels of nitrogenous constituents such as proteins, individual amino acids, and nucleic acids (Hoffmann 1990; Isbrucker and Burdock 2006). According to Zhang and Ye (2009) more than 400 compounds have been 
isolated from Glycyrrhiza species, where triterpene saponins and flavonoids are the main constituents which showed broad biological activity.

\section{Flavonoids}

It has been reported that more than 300 flavonoids have been found in various species of Glycyrrhiza (Herz et al. 1998; Li et al. 2000). Among them the commonly used flavonoid types are flavanones, chalcones, isoflavanes, isoflavenes, flavones, and isoflavones (Lou and Qin 1995; Xing et al. 2003). G. glabra has yellow color due to the flavonoids, e.g., liquiritin and isoliquiritin (Yamamura et al. 1992). A number of licorice flavonoids were identified: liquiritin, liquiritigenin, rhamnolliuiritin, liquiritin apioside, gralbranin, glabrol, licoflavanone, isoliquiritigenin, neoisoliquiritin, licuraside, licochalcone $\mathrm{A}$ and $\mathrm{B}$, licoricidin, 7-methillicoricidin, hispaglabridin A and B, liocflavone A and B, liocflavanol, glyzaglabrin, licoisoflavanone, glabroisoflavanone, glabrone, licoricone, and gancaonin (Zhang and Ye 2009).

Hatano et al. (1998) isolated flavonoid glycosides with feruloyl or coumaroyl groups and with an indole conjugate. Ma et al. (2005) isolated and identified bioactive flavonoid compounds, liquiritigenin and isoliquiritigenin, from the crude extract of G. uralensis Risch. Franceschelli et al. (2011) identified licochalcone C, the structural isomer of licochalcone A. Other flavonoids such as licoagrodin, licoagrochalcones, glyinflanin B, and glycyrdione A were also reported by several studies (Asl and Hosseinzadeh 2008; Christensen and Kharazmi 2001; Li et al. 2000). Gupta et al. (2008) identified glabridin and hispaglabridin B from ethanolic extract of the roots of G. glabra.

Manfredi et al. (2001) isolated and identified bioactive compounds glepidotin B and glepidotin A from the extract of G. lepidota. Williamson (2003) isolated and identified isoflavonoid derivatives, namely glabridin, galbrene, glabrone, shinpterocarpin, licoisoflavones $\mathrm{A}$ and $\mathrm{B}$, formononetin, glyzarin, and kumatakenin. In other studies hispaglabridin A, hispaglabridin $\mathrm{B}, 4^{\prime}-O$-methylglabridin, and $3^{\prime}$-hydroxy$4^{\prime}$-O $O$-methylglabridin were identified from Glycyrrhiza species. Won et al. (2007) isolated and identified licochalcone A from the ethyl acetate extract of the roots of G. uralensis. Kinoshita et al. (2005) identified several compounds from the root of G. glabra, namely glabridin, galbrene, glabrone, shinpterocarpin, licoisoflavones A and B, formononetin, glyzarin, kumatakenin, hispaglabridin A, hispaglabridin B, glabroisoflavanone A and B, and glabroisoflavanone B. 


\section{Saponins}

The root of Glycyrrhiza contains triterpenoid saponins (glycyrrhizin, glycyrrhizic acid), which are the major characteristic constituents of liquorice, and they are responsible for the sweet taste (Blumenthal et al. 2000). Glycyrrhizic acid is the major triterpenoid saponin in licorice root and the main sweetener of the herb which is 50 times sweeter than sugar (Nomura et al. 2002). Glycyrrhizin and the aglycone of glycyrrhizin are believed to speed the healing of gastric ulcers (Amirova 1993; Blumenthal et al. 2000). Glycyrrhetic acid has shown anti-inflammatory and antiarthritic activities in animal studies (Amirova 1993). Isbrucker and Burdock (2006) described other triterpenes, namely liquiritic acid, glycyrretol, glabrolide, isoglaborlide, and licorice acid.

Fenwick et al. (1990) described two aglycone forms of glycyrrhizic acid $18 \beta$-glycyrrhetinic acid and 18 $\alpha$-glycyrrhetinic acid. Vashist and Sharma (2013) reported about the presence of ammonium glycyrrhizinate (3.4\%) and calcium glycyrrhizinate (4\%) in the ethanolic extract of G. glabra. Zhang and Ye (2009) described several saponins derived from Glycyrrhiza species, namely licorice-saponin A3, $22 \beta$-actoxylglycyrrhizin, uralsaponin B, apioglycyrrhizin, araboglycyrrhizin, and icorice-saponin E2.

\section{Phenolic Compounds}

There are many reports on the phenolic constituents of Glycyrrhiza species (Nomura and Fukai 1998). The main phenols include liquiritin, isoliquiritin, liquiritin apioside, and isoprenoid-substituted flavonoids, chromenes, coumarins, and dihydrostilbenes. Nomura et al. (2002) studied phenolic compounds from various Glycyrrhiza species, and found isoprenoid-substituted flavonoid (pyranoisoflavan, glabridin) ( $G$. glabra), isoflavans (G. uralensis), licochalcone A (G. inflate, G. eurycarpa), licoricidin (6), and licorisoflavan A (G. aspera). For example isobavachin is observed in G. pallidiflora, sigmoidin B in G. uralensis, and liquiritigenin in Glycyrrhiza species (Nomura and Fukai 1998).

Zhang and Ye (2009) described several phenolic compounds derived from Glycyrrhiza species including glycycoumarin, glabrocoumarin, glycyrin, inflacoumarin A, licopyranocoumarin, isoglycerol, neoglycerol, licobenzofuran, licocoumarone, glabrocoumarone, gancaonin, and kanzonol. In another study Ammar et al. (2012) isolated phenolic compounds, namely liquiriteginin, liquiritin apioside, neoliquiritin apioside, isoliquiritin, isoliquritin apioside, licuraside2-(5- $P$-coumaryl apiosyl), and isoliquiritin from the total polar extract of G. glabra utilizing different chromatographic techniques.

Isolation and identification of isoliquiritigenin from licorice grown in China have been reported by Chin et al. (2007) and liquiritin by Huang et al. (2010). 
Zhu et al. (2008) studied biologically active compounds of $G$. uralensis collected in Mongolia and found three flavanone constituents (liquiritin apioside, liquiritin, and liquiritigenin) and three chalcones (isoliquiritin apioside, isoliquiritin, and isoliquiritigenin). Similar observation was reported by Williamson (2003) who identified liquiritin, liquiritigenin, rhamnoliquiritin, neoliquiritin, chalcones isoliquiritin and isoliquiritigenin, neoisoliquiritin, licuraside, glabrolide, and licoflavonol.

\section{Coumarins}

Several coumarins were identified from G. glabra including liqcoumarin, glabrocoumarone A and B, herniarin, umbelliferone, and glycyrin (Williamson 2003). Kinoshita et al. (2005) studied coumarins from the Glycyrrhiza plants and identified liqcoumarin, glabrocoumarone A and B, herniarin, umbelliferone, glycocoumarin, licofuranocoumarin, licopyranocoumarin, and glabrocoumarin. In recent studies Qiao et al. (2014) identified glycerol, glycycoumarin, and dehydroglyasperin from the root extract of G. uralensis. De Simone et al. (2001) described two coumarins of G. glabra, glycocoumarin and licopyranocoumarin, which were able to inhibit giant cell formation in HIV-infected cell cultures.

\section{Essential Oils and Other Compounds}

Other secondary metabolites such as fatty acids, phenol, guaiacol, asparagines, glucose, sucrose, starch, polysaccharides, and sterols ( $\beta$-sitosterol, dihydrostigmasterol) have also been found and reported by Näf and Jaquier (2006).

Ali (2013) studied essential oil composition of G. glabra and found compounds such as $\alpha$-pinene, $\beta$-pinene, octanol, $\gamma$-terpinene, stragole, isofenchon, $\beta$-caryophyllene, citronellyl acetate, caryophyllene oxide, and geranyl hexanolate. Among those compounds geranyl hexanolate represents higher percentage $(34 \%)$ whereas $\beta$-pinene was the lowest (1.7\%). Khalaf et al. (2010) studied phytoestrogens from roots of G. glabra from Syria and identified daidzein, daidzin, genistin, ononin, glycitein, genistein, and coumestrol. Sultana et al. (2010) described dihydrostilbenes from the root extract of G. glabra grown in Sicily.

\section{Side Effects and Toxicity}

The potentially toxic compounds in licorice are unconfirmed, although deglycyrrhinized licorice (DGL) is reported to be free of adverse effects. The toxic effects of licorice are well documented. Large amounts of licorice may result in severe 
Table 2. Summary of contradictions and drug interactions of licorice

\begin{tabular}{l|l}
\hline Contradictions & Drug interactions \\
\hline Kidney insufficiency & Cardiac glycosides \\
High blood pressure & Laxatives \\
Low blood pressure & Diuretics \\
Cardiac disease & Thiazides \\
Prolonged use & Corticoid treatment \\
Pregnancy & Hydrocortisone \\
Cirrhosis & Insulin \\
Chronic hepatitis & \\
Ex-alcoholics & \\
Obesity & \\
Diabetes & \\
\hline
\end{tabular}

hypertension, hypokalemia, and other signs of mineralocorticoid excess (Asl and Hosseinzadeh 2008).

Large doses (more then ten times the standard dose) taken over a long period of time can lead to a number of dangerous conditions (McGuffin et al. 1997). The use of licorice is contradicted in persons with high blood pressure due to hypertension caused by overuse of licorice (Olukoga and Donaldson 2000). This is thought to be due to the effect of licorice on the aldosterone system (Sharma and Agrawal 2013). Al-Qarawi et al. (2002) report the treatment with licorice extract resulted in dosedependent increases in plasma renin and sodium with concomitant decreases in plasma cortisol, adrenocorticotropic hormone (ACTH), aldosterone, and potassium levels.

Prolonged use of licorice could result in hypertension, hypokalemia, and edema (DeSmet et al. 1997; Asl and Hosseinzadeh 2008). It is also speculated that since insulin-dependent diabetics appear to be predisposed to hypokalemia and sodium retention, licorice use is contradicted by diabetes (McGuffin et al. 1997; Isbrucker and Burdock 2006).

Licorice should not be used with stimulant laxatives or hypotensive diuretics (such as thiazides) because of the potassium loss associated with the laxatives and diuretics (DeSmet et al. 1997; Asl and Hosseinzadeh 2008). In earlier studies glycyrrhizin has been shown to interfere with $5 \beta$-reductase breakdown of corticosteroids, thus prolonging the biological half-life of these steroids. The licorice constituent glycyrrhizin or the aglycone, glycyrrhetinic acid, may increase the effect of corticoid treatment (Brinker 1997) (Table 2).

\section{Conclusion}

Licorice (Glycyrrhiza) a leguminous plant and the roots have been used worldwide as a medicine and flavor in industry. It is estimated that more than 400 compounds have been isolated from Glycyrrhiza species, where triterpene saponins and flavonoids are the main constituents which showed broad biological activity. The 
triterpenoid saponins (glycyrrhizin, glycyrrhizic acid), which are the major characteristic constituents of liquorice, are responsible for the sweet taste. The main phenols include liquiritin, isoliquiritin, and coumarins including liqcoumarin and glabrocoumarone A and B. Pharmacological studies have confirmed that plant extracts and individual biologically active compounds exhibit a broad range of biological activities such as antimicrobial, antiviral, anti-ulcer, antitumor, antioxidant, antiallergic, neuroprotective, anti-inflammatory, hepatoprotective, and dermatological activities. The Glycyrrhiza plant can also be used in the management of impaired learning, dementia, and Alzheimer's disease. The potentially toxic compounds in licorice are unconfirmed, whereas the toxic effects of licorice plant are well documented. Large doses taken over a long period of time can lead to a number of severe disorders. From these data and reports it can be concluded that licorice can be used as a therapeutic drug in low doses for major body ailments and presents no concern for safe use.

\section{References}

Adel M, Alousi LA, Salem HA (2005) Licorice: a possible anti-inflammatory and anti-ulcer drug. AAPS PharmSciTech 6:74-82

Akhtar N, Khan MS, Iqbal A, Khan BA, Bashir S (2011) Glycyrrhiza glabra extract cream: effect on skin pigment melanin. In: Proceeding book of international conference on bioscience, biochemistry and bioinformatics IPCBEE. IACSIT Press, Singapore

Ali EM (2013) Phytochemical composition, antifungal, antiaflatoxigenic, antioxidant, and anticancer activities of Glycyrrhiza glabra L. and Matricaria chamomilla L. essential oils. J Med Plants Res 7(29):2197-2207

Al-Qarawi AA, Abdel-Rahman HA, Ali BH, El Mougy SA (2002) Liquorice (Glycyrrhiza glabra) and the adrenal-kidney-pituitary axis in rats. Food Chem Toxicol 40(10):1525-1527

Al-Razzuqi RAM, Al-Jawad FH, Al-Hussaini JA, Al-Jeboori AA (2012) Hepatoprotective effect of Glycyrrhiza glabra in carbon tetrachloride-induced model of acute liver injury. J Phys Pharm Adv 2(7):259-263

Ambawade S, Kasture VS, Kasturi SB (2001) Anxiolytic activity of Glycyrrhiza glabra Linn. J Nat Remedies 2:130-134

Amirova GS (1993) Licorice in Azerbaijan (in Russian). Elm, Baku 104 pp

Anon (2005) Glycyrrhiza glabra. Altern Med Rev 10:230-237

Armanini D, Fiore C, Mattarello MJ, Bielenberg J, Palermo M (2002) History of the endocrine effects of licorice. Exp Clin Endocrinol Diabetes 110:257-261

Asgary S, Jafari Dinani N, Madani H, Mahzoni P, Nader G (2007) Effect of Glycyrrhiza glabra extract on aorta wall atherosclerotic lesion in hypercholesterolemic rabbits. Pak J Nutr 6(4):313-317

Asl MN, Hosseinzadeh H (2008) Review of pharmacological effects of Glycyrrhiza sp. and its bioactive compounds. Phytother Res 22:709-724

Bennett A, Clark-Wibberley T, Stamford IF, Wright JE (1980) Aspirin-induced gastric mucosal damage in rats: cimetidine and deglycyrrhizinated liquorice together give greater protection than low doses of either drug alone. J Pharm Pharmacol 32:151

Biondi DM, Rocco C, Ruberto G (2005) Dihydrostilbene derivatives from Glycyrrhiza glabra leaves. J Nat Prod 68:1099-1102

Blumenthal M, Goldberg A, Brinckmann J (2000) Herbal medicine: expanded commission E monographs. Integrative Medicine Communications, Newton, MA 
Brinker F (1997) Herb contradictions and drug interactions. Eclectic Medical Publications, Sandy, Portland, OR

Brown K (1995) Medicinal plants, indigenous medicine and conservation of biodiversity in Ghana. In: Swanson T (ed) Intellectual property rights and biodiversity conservation. Cambridge University Press, Cambridge, pp 201-231

Cai Y, Luo Q, Sun M, Corke HA (2004) Antioxidant activity and phenolic compounds of 112 traditional Chinese medicinal plants associated with anticancer. Life Sci 74:2157-2184

Chakravarthi KK, Vadhani RA, Narayan RS (2012) Effect of Glycyrrhiza glabra root extract on learning and memory in wistar albino rats. Int J Biol Med Res 3(3):2059-2064

Chen F, Chan KH, Jiang Y, Kao RYT, Lu HT, Fan KW, Cheng VCC, Tsui WHW, Hung IFN, Lee TSW, Guan Y, Peiris JSM, Yuen KY (2004) In vitro susceptibility of 10 clinical isolates of SARS coronavirus to selected antiviral compounds. J Clin Virol 31:69-75

Chevallier A (1996) Encyclopedia of medicinal plants. Dorling Kindersley Pty Limited, St Leonards

Chin YW, Jung HA, Liu Y, Su BN, John A, Castoro WJ, Keller MA, Douglas K (2007) Anti oxidant constituents of the roots and stolons of licorice (Glycyrrhiza glabra). J Agric Food Chem 55(1):4691-4696

Christensen SB, Kharazmi A (2001) Antimalarial natural products. In: Tringali C (ed) Bioactive compounds from natural sources: isolation, characterization and biological properties. Taylor \& Francis, New York, pp 379-432

Cinati J, Morgenstern B, Bauer G, Chandra P, Rabenau H, Doerr HW (2003) Glycyrrhizin, an active component of liquorice roots, and replication of SARS-associated coronavirus. Lancet 361:2045-2046

Crance JM, Biziagos E, Passagot J, Van Cuyuck-Gandré H, Deloince DR (1990) Inhibition of hepatitis A virus replication in vitro by antiviral compounds. J Med Virol 31:155-160

Crance JM, Scaramozzino N, Jouan A, Garin D (2003) Interferon, ribavirin, 6-azarridine and glycyrrhizin: antiviral compounds active against pathogenic flaviviruses. Antiviral Res 58:73-79

Curreli F, Friedman K, Alvin E, Flore O (2007) Protective mechanism of glycyrrhizin on acute liver injury induced by carbon tetrachloride in mice. Biol Pharm Bull 30(10):1898-1904

Da Nagao Y, Sata M, Suzuki H, Tanikawa K, Itoh K, Kameyama T (1996) Effectiveness of glycyrrhizin for oral lichen planus in patients with chronic HCV infection. J Gastroenterol 31:691-695

Davis EA, Morris DJ (1991) Medicinal uses of licorice through the millennia: the good and plenty of it. Mol Cell Endocrinol 78:1-6

DeSmet PAGM, Keller K, Hansel R, Chandler RF (1997) Adverse effects of herbal drugs, vol 2-3. Springer, Berlin

Dhingra D, Sharma A (2005) Evaluation of antidepressant-like activity of glycyrrhizin in mice. Indian J Pharmacol 37:390-394

Dhingra D, Sharma A (2006) Antidepressant-like activity of Glycyrrhiza glabra L. in mouse models of immobility tests. Prog Neuropsychopharmacol Biol Psychiatry 30:449-454

Dong S, Inoue A, Zhu Y, Tanji M, Kiyama R (2007) Activation of rapid signaling pathways and the subsequent transcriptional regulation of breast cancer MCF-7 by the treatment with an extract of Glycyrrhiza glabra root. Food Chem Toxicol 45:2470-2478

Fatima A, Gupt VK, Luqman S, Negi AS, Kumar JK, Shanker K, Saikia D, Srivastava S, Darokar MP, Khanuja SPS (2009) Antifungal activity of Glycyrrhiza glabra extracts and its constituent glabridin. Phytother Res 23:1990-1993

Fenwick GR, Lutomski J, Nieman C (1990) Liquorice, Glycyrrhiza glabra L. composition, uses and analysis. Food Chem 38:119-143

Fiore C, Eisenhut M, Ragazzi E, Zanchin G, Armanini D (2005) A history of the therapeutic use of liquorice in Europe. J Ethnopharmacol 99:317-324

Fiore C, Eisenhut M, Krausse R, Ragazzi E, Pellati D, Armanini D, Bielenberg J (2009) Antiviral effects of Glycyrrhiza species. Am J Chin Med 37(2):383-394

Firn R (2010) Nature's chemicals: the natural products that shaped our world. Oxford University Press, Oxford, pp 74-75 
Franceschelli S, Pesce M, Vinciguerra I, Ferrone A, Riccioni G, Patruno A, Grilli A, Felaco M, Speranza L (2011) Licocalchone-C extracted from Glycyrrhiza glabra inhibits lipopolysaccharide-interferon-gamma inflammation by improving antioxidant conditions and regulating inducible nitric oxide synthase expression. Molecules 16:5720-5734

Fuhrman B, Volkova N, Kaplan M, Presser D, Attias J, Hayek T, Aviram M (2002) Antiatherosclerotic effect of licorice extract supplementation on hypercholestrolomic patients. Nutr., 18:268-273

Fujisawa Y, Sakamoto M, Matsushita M, Fujita T, Nishioka K (2000) Glycyrrhizin inhibits the lytic pathway of complement-possible mechanism of its anti-inflammatory effect on liver cells in viral hepatitis. Microbiol Immunol 44(9):799-804

Fukai T, Cai BS, Maruno K, Miyakawa Y, Konishi M, Nomura T (1998) An isoprenylated flavanone from Glycyrrhiza glabra and rec-assay of licorice phenols. Phytochemistry 49(7):2005-2013

Fukai T, Ali M, Kaitou K, Kanda T, Terada S, Nomura T (2002) Anti-Helicobacter pylori flavonoids from licorice extract. Life Sci 71:1449-1463

Furuhashi I, Iwata S, Shibata S, Sato T, Inoue H (2005) Inhibition by licochalcone A, a novel flavonoid isolated from liquorice root, of IL-1 $\beta$-induced PGE2 production in human skin fibroblasts. J Pharm Pharmacol 57:1661-1666

Gareri P, Condorelli D, Belluardo N, Russo E, Loiacono A, Barresi V, Trovato-Salinaro A, Mirone MB, Ferreri Ibbadu G, De Sarro G (2004) Anticonvulsant effects of carbenoxolone in genetically epilepsy prone rats (GEPRs). Neuropharmacology 47(8):1205-1216

Gupta VK, Fatima A, Faridi U, Negi AS, Shanker K, Kumar JK, Rahuja N, Luqman S, Sisodia BS, Saikia DS, Darokar MP, Khanuja SPS (2008) Antimicrobial potential of Glycyrrhiza glabra roots. J Ethnopharmacol 116:377-380

Hatano T, Takagi M, Ito H, Yoshida T (1998) Acylated flavonoid glycosides and accompanying phenolics from licorice. Phytochemistry 47:287-293

Hatano T, Shintani Y, Aga Y, Shiota S, Tsuchiya T, Yoshida T (2000) Phenolic constituents of licorice. VIII. Structures of glicophenone and glicoisoflavanone, and effects of licorice phenolics on methicillin resistant Staphylococcus aureus. Chem Pharm Bull 48:1286-1292

Hattori T, Ikematsu S, Koito A, Matsushita S, Maeda Y, Hada M, Fujimaki M, Takatsuki K (1989) Preliminary evidence for inhibitory effect of glycyrrhizin on HIV replication in patients with AIDS. Antiviral Res 11:255-261

Hayash H, Hattori S, Inoue K, Khodzhimatov O, Ashurmetov O, Ito M, Honda G (2003) Field survey of Glycyrrhiza plants in Central Asia: chemical characterization of G. glabra collected in Uzbekistan. Chem Pharm Bull 51(11):1338-1340

Herz W, Kirby GW, Moore RE, Steglich W, Tamm C (1998) Fortschritte der Chemie Organischer Naturstoffe, vol 73. Springer, New York

Hesham RE, Shgeru N (2002) Chemistry of bioflavonoids. Indian J Pharm Educ 36:191-194

Hoffman D (2000) Easy breathing: natural treatments for asthma, colds, flu, coughs, allergies, sinusitis. Storey Books, Pownal, VT

Hoffmann D (1990) The new holistic herbal, 2nd edn. Element, Shaftesbury

Hojo H, Sato J (2002) Antifungal activity of licorice (Glycyrrhiza glabra) and potential applications in beverage. Foods Food Ingred J 203:27-33

Hong ND, Koo BH, Joo SM, Lee SK (1988) Studies on the efficacy of combined preparation of crude drugs. Effects of sipmidojuksan on the central nervous and cardiovascular systems. Korean J Pharmacol 19(2):141

Hossain MS, Hossain MA, Islam R, Alam AH, Zahan K, Sarkar S, Farooque MA (2004) Antimicrobial and cytotoxic activities of 2-aminobenzoic acid and 2-aminophenol and their coordination complexes with magnesium (Mg-II). Pak J Biol Sci 7:25-27

Hsu YL, Kuo PL, Chiang LC, Lin CC (2004) Isoliquiritigenin inhibits the proliferation and induces the apoptosis of human non-small cell lung cancer A549 cells. Clin Exp Pharmacol Physiol 31(7):414-418

Huang M, Wang W, Wei S (2010) Investigation on medicinal plant resources of Glycyrrhiza uralensis in China and chemical assessment of its underground part. J Nat Med 63(2):137-146

Huxley A (1992) Dictionary of gardening. Stockton Press, New York 
Isbrucker RA, Burdock GA (2006) Risk and safety assessment on the consumption of licorice root (Glycyrrhiza sp.), its extract and powder as a food ingredient, with emphasis on the pharmacology and toxicology of glycyrrhizin. Regul Toxicol Pharmacol 46:167-192

Jeong HG, You HJ, Park SJ, Moon AR, Chung YC, Kang SK, Chun HK (2002) Hepatoprotective effects of 18ß-glycyrrhetinic acid on carbon tetrachloride-induced liver injury: inhibition of cytochrome P450 2E1 expression. Pharm Res 46:221-227

Jo EH, Kim SH, Ra JC, Kim SR, Cho SD, Jung JW, Yang SR, Park JS, Hwang JW, Aruoma OI, Kim TY, Lee YS, Kang KS (2005) Chemopreventive properties of the ethanol extract of Chinese licorice (Glycyrrhiza uralensis) root: induction of apoptosis and G1 cell cycle arrest in MCF-7 human breast cancer cells. Cancer Lett 230:239-247

Kakegawa H, Matsumoto H, Satoh T (1992) Inhibitory effects of some natural products on the activation of hyaluronidase and their anti-allergic actions. Chem Pharm Bull 40:1439-1442

Kanazawa M, Satomi Y, Mizutani Y, Ukimura O, Kawauchi A, Sakai T, Baba M, Okuyama T, Nishino H, Miki T (2003) Isoliquiritigenin inhibits the growth of prostate cancer. Eur Urol 43(5):580-586

Kang JS, Yoon YD, Cho IJ, Han MH, Lee CW, Park SK, Kim HM (2005) Glabridin, an isoflavan from licorice root, inhibits inducible nitric-oxide synthase expression and improves survival of mice in experimental model of septic shock. J Pharmacol Exp Ther 312(3):1187-1194

Kar A (2007) Pharmacognosy and pharmacobiotechnology. New Age International Ltd Publishers, New Delhi, pp 332-600

Khalaf I, Vlase L, Lazăr D, Corciovă A, Ivãnescu B, Lazăr MI (2010) Hplc-Ms study of phytoestrogens from Glycyrrhiza glabra. Farmacia 58(1):89-94

Kinoshita T, Tamura Y, Mizutani K (2005) The isolation and structure elucidation of minor isoflavonoids from licorice of Glycyrrhiza glabra origin. Chem Pharm Bull 53:847-849

Kong ND, Chang IK, Lee SI, Kim NJ (1984) Studies on the efficacy of combined preparation of crude drugs: effects of "Bojungikgi-tang" on the digestive system, blood pressure and diuretic actions. Korean J Pharmacog 15(3):121-127

Kroes BH, Beukelman CJ, van den Berg AJ, Wolbink GJ, van Dijk H, Labadie RP (1997) Inhibition of human complement by beta-glycyrrhetinic acid. Immunology 90(1):115-120

Kuo KK, Chang JS, Wang KC, Chiang LC (2009) Water extract of Glycyrrhiza uralensis inhibited enterovirus 71 in a human foreskin fibroblast cell line. Am J Chin Med 37(2):383-394

Lateef M, Iqba L, Fatima N, Siddiqui K, Afza N, Zia-ul-Haq M, Ahmad M (2012) Evaluation of antioxidant and urease inhibition activities of roots of Glycyrrhiza glabra. Pak J Pharm Sci 25:99-102

Lee KT, Kim BJ, Kim HJ, Heo MY, Kim HP (1997) Biological screening of 100 plant extracts for cosmetic use (I): inhibitory activities of tyrosinase and DOPA auto-oxidation. Int J Cosmet Sci 19:291-298

Lee J, Jung E, Park J, Jung K, Park J, Kim J, Hong S, Park J, Park S, Lee S, Park D (2005) Glycyrrhizin induces melanogenesis by elevating a camp level in b16 melanoma cells. J Invest Dermatol 124:405-411

Li W, Asada Y, Yoshikawa T (2000) Flavonoid constituents from Glycyrrhiza glabra hairy root cultures. Phytochemistry 55:447-456

Liu W, Kato M, Akhand A, Hayakawa A, Takemura M, Yoshida S, Suzuki H, Nakashima I (1998) The herbal medicine Sho-saiko-to inhibits the growth of malignant melanoma cells by upregulating Fas mediated apoptosis and arresting cell cycle through down regulation of cyclin dependent kinases. Int J Oncol 12:1321-1326

Lou ZC, Qin B (1995) Species systematization and quality evaluation of commonly used Chinese traditional drugs. North ed, vol 1-3. Beijing Medical University Press and Peking Union Medical College Press, Beijing, p 19

Lucas (1976) Nature's medicines. Melvin Powers, Wilshire Book Company, Hollywood, CA

Ma CJ, Li GS, Zhang DL, Liu K, Fan X (2005) One step isolation and purification of liquiritigenin and isoliquiritigenin from Glycyrrhiza uralensis Risch. using high-speed counter-current chromatography. J Chromatogr 1078:188-192 
Madziga HA, Sanni S, Sandabe UK (2010) Phytochemical and elemental analysis of Acalypha wilkesiana leaf. J Am Sci 6(11):510-514

Manfredi KP, Vallurupalli V, Demidova M, Kindscher K, Pannell LK (2001) Isolation of an antiHIV diprenylated bibenzyl from Glycyrrhiza lepidota. Phytochemistry 58:153-157

Martinez MJA, Lazaro RM, del Olmo LMB, Benito PB (2008) Anti-infectious activity in the Anthemideae tribe. Stud Nat Prod Chem 35:445-516

Masoomeh MJ, Kiarash G (2007) In vitro susceptibility of Helicobacter pylori to licorice extract. Iran J Pharm Res 6:69-72

Matsui S, Matsumoto H, Sonoda Y, Ando K, Aizu-Yokota E, Sato T, Kasahara T (2004) Glycyrrhizin and related compounds down-regulate production of inflammatory chemokines IL-8 and eotaxin 1 in a human lung fibroblast cell line. Int Immunopharmacol 4(13):1633-1644

Maurya R, Singh G, Yadav PP (2008) Antiosteoporotic agents from natural sources. Stud Nat Prod Chem 35:517-545

McGuffin M, Hobbs C, Upton R, Goldberg A (1997) Botanical safety handbook. CRC Press, Boca Raton, FL

Meghashri SG (2009) In vitro antifungal and antibacterial activities of root extract of Glycyrrhiza glabra. J Appl Sci Res 5:1436-1439

Mills SY, Bone K (2000) Principles and practice of phytotherapy: modern herbal medicine. Churchill Livingstone, London

Mishra NK, Bstia S, Mishra G, Chowdary KA, Patra S (2011) Anti-arthritic activity of Glycyrrhiza glabra, Boswellia serrata and their synergistic activity in combined formulation studied in Freund's adjuvant induced arthritic rats. J Pharm Educ Res 2:92-98

Muralidharan P, Balamurugan G, Babu V (2009) Cerebroprotective effect of Glycyrrhiza glabra Linn. root extract on hypoxic rats. Bangladesh J Pharmacol 4:60-64

Näf R, Jaquier A (2006) New lactones in liquorice (Glycyrrhiza glabra L.). Flavour Fragr J 21:193-197

Nand P, Drabu S, Gupta R (2012) Phytochemical and antimicrobial screening of medicinal plants for the treatment of acne. Indian J Nat Prod Res 3(1):28-32

Nerya O, Vaya J, Musa R, Izrael S, Ben-Arie R, Tamir S (2003) Glabrene and isoliquiritigenin as tyrosinase inhibitors from liquorice roots. J Agric Food Chem 51(5):1201-1207

Nitalikar MM, Munde KC, Dhore BV, Shikalgar SN (2010) Studies of antibacterial activities of Glycyrrhiza glabra root extract. Int J PharmTech Res 2(1):899-901

Nomura T, Fukai T (1998) Phenolic constituents of licorice (Glycyrrhiza species). In: Herz W, Kirby GW, Moore RE, Steglich W, Ch T (eds) Progress in the chemistry of organic natural products. Springer, Wien, pp 1-140

Nomura T, Fukai T, Akiyama T (2002) Chemistry of phenolic compounds of licorice (Glycyrrhiza species) and their estrogenic and cytotoxic activities. Pure Appl Chem 74(7):1199-1206

Olukoga A, Donaldson D (2000) Liquorice and its health implications. J R Soc Promot Health 120:83-89

Orlent H, Hansen BE, Willems M, Brouwer JT, Huber R, Kullak-Ublick GA, Gerken G, Zeuzem S, Nevens F, Tielemans WSM, Zondervan PE, Lagging M, Westin J, Schalme SM (2006) Biochemical and histological effects of 26 weeks of glycyrrhizin treatment in chronic hepatitis C: a randomized phase II trial. J Hepatol 45(4):539-546

Öztürk M, Altay V, Hakem KR, Akçiçek E (2017) Liquorice-from botany to phytochemistry, Springer briefs in plant sciences. Springer Nature, Basel, 139 pp. https://doi. org/10.1007/978-3-319-74240-3

Patil SM, Patil MB, Sapkale GN (2009) Antimicrobial activity of Glycyrrhiza glabra Linn. Roots. Int J Chem Sci 7(1):585-591

Pellatti D, Fiore C, Armanini D, Rassu M, Bertoloni G (2009) In vitro effects of glycyrrhetinic acid on the growth of clinical isolates of Candida albicans. Phytother Res 23:572-574

Plyasunova OA, Egoricheva IN, Fedyuk NV, Pokrovsky AG, Baltina LA, Murinov YI, Tolstikov GA (1992) Antiviral activity of licorice. Voprosy Virusologii 37:235-238 
Puupponen-Pimiä R, Nohynek L, Meier C, Kähkönen M, Heinonen M, Hopia A, OksmanCaldentey KM (2001) Antimicrobial properties of phenolic compounds from berries. J Appl Microbiol 90:494-507

Qiao X, Liu CF, Ji S, Lin XH, Guo DA, Ye M (2014) Simultaneous determination of five minor coumarins and flavonoids in Glycyrrhiza uralensis by solid-phase extraction and highperformance liquid chromatography/electrospray ionization tandem mass spectrometry. Planta Med 80(2-3):237-242

Rahman MS, Rashid MA (2008) Antimicrobial activity and cytotoxicity of Eclipta prostrata. Oriental Pharm Exp Med 8:47-52

Ram A, Mabalirajan U, Das M, Bhattacharya I, Dinda AK, Gangal SV, Ghosh B (2006) Glycyrrhizin alleviates experimental allergic asthma in mice. Int Immunopharm 6(9): 1468-1477

Reid D (2001) A handbook of Chinese healing herbs. Periplus, Singapore

Salvi M, Fiore C, Armanini D, Toninello A (2003) Glycyrrhetinic acid-induced permeability transition in rat liver mitochondria. Biochem Pharmacol 66:2375-2379

Sarker SD, Nahar L (2007) Chemistry for pharmacy students: general, organic and natural product chemistry. Wiley, London

Satomi Y, Nishino H, Shibata S (2005) Glycyrrhetinic acid and related compounds induce G1 arrest and apoptosis in human hepatocellular carcinoma HepG2. Anticancer Res 25(6):4043-4047

Saxena S (2005) Glycyrrhiza glabra: medicine over the millennium. Nat Prod Radiance 4(5):358-367

Schulz V, Hänsel R, Tyler VE (1998) Rational phytotherapy. A physicians' guide to herbal medicine. Springer, Berlin, pp 160-187

Sharma V, Agrawal RC (2013) Glycyrrhiza glabra-a plant for the future. J. Pharm Med Scien 2(3): $15-20$

Sharma V, Agrawal RC, Pandey S (2013) Phytochemical screening and determination of antibacterial and anti-oxidant potential of Glycyrrhiza glabra root extracts. J Environ Res Dev 7(4):1552-1558

Sheehan MP, Atherton DJ (1992) A controlled trial of traditional Chinese medicinal plants in widespread non-exudative atopic eczema. Br J Dermatol 126(2):179-184

Sheela ML, Ramakrishna MK, Salimath BP (2006) Angiogenic and proliferative effects of the cytokine VEGF in Ehrlich ascites tumor cells is inhibited by Glycyrrhiza glabra. Int Immunopharmacol 6:494-498

Shin EM, Zhou HY, Guo LY, Kim JA, Lee SH, Merfort I, Kang SS, Kim SM, Kim S, Kim YS (2008) Anti-inflammatory effects of glycyrol isolated from Glycyrrhiza uralensis in LPSstimulated RAW264.7 macrophages. Int Immunopharmacol 8:1524-1532

Shinwari ZK, Khan I, Naz S, Hussain A (2009) Assessment of antibacterial activity of three plants used in Pakistan to cure respiratory diseases. Afr J Biotechnol 8(24):7082-7086

Shiota G, Harada K, Ishida M, Tomie Y, Okubo M, Katayama S, Ito H, Kawasaki H (1999) Inhibition of hepatocellular carcinoma by glycyrrhizin in diethylnitrosamine-treated mice. Carcinogenesis 20:59-63

Shirinyan E, Panosyan A, Barikyan M, Avakyan O (1988) New antistressor compounds from licorice. Izv Akad Nauk USSR 6:932-936 (in Russian)

Singh M (2010) Comparative phytochemical and antioxidant study of aqueous extracts of Glycyrrhiza glabra (mulethi) and Piper longum (long pepper). Int J Drug Res Technol 2:203-207

Siracusa L, Saija A, Cristani M, Cimino F, D’Arrigo M, Trombetta D, Rao F, Ruberto G (2011) Phytocomplexes from liquorice (Glycyrrhiza glabra L.) leaves-chemical characterization and evaluation of their antioxidant, anti-genotoxic and anti-inflammatory activity. Fitoterapia 82(4):546-556 
Sitohy MZ, El-Massry RA, El-Saadany SS, Labib SM (1991) Metabolic effect of licorice roots (Glycyrrhiza glabra) on lipid distribution pattern, liver and renal functions of albino rats. Nahrung 35:799-806

Škrovánková S, Mišurcová L, Machů L (2012) Chapter 3-Antioxidant activity and protecting health effects of common medicinal plants. Adv Food Nutr Res 67:75-139

Sokolov S, Zamotayev I (1985) Directory of medicinal plants. Medicina, Moscow (in Russian)

Statti GA, Tundis R, Sacchetti G, Muzzoli M, Bianchi A, Menichini F (2004) Variability in the content of active constituents and biological activity of Glycyrrhiza glabra. Fitoterapia 75:371-374

Subramoniam A, Pushpangadan P (1999) Development of phytomedicines for liver diseases. Indian J Pharmacol 31:166-175

Sultana S, Haque A, Hamid K, Urmi KF, Roy S (2010) Antimicrobial, cytotoxic and antioxidant activity of methanolic extract of Glycyrrhiza glabra. Agric Biol J North Am 1(5):957-960

Tamir S, Eizenberg M, Somjen D, Stern N, Shelach R, Kaye A, Vaya J (2000) Estrogenic and antiproliferative properties of glabridin from licorice in human breast cancer cells. Cancer Res 60:5704-5709

Tanaka Y, Kikuzaki H, Fukuda S, Nakatani N (2001) Antibacterial compounds of licorice against upper airway respiratory tract pathogens. J Nutr Sci Vitaminol 47:270-273

Tandon A, Tandon BN, Bhujwala RA (2002) Clinical spectrum of acute sporadic hepatitis E and possible benefit of glycyrrhizin therapy. Hepatol Res 23:55-61

Tharkar PR, Tatiya AU, Shinde PR, Surana SJ, Patil UK (2010) Antifungal activity of Glycyrrhiza glabra Linn. and Emblica officinalis Gaertn. by direct bioautography method. Int J Pharm Res 2:1547-1549

Tokiwa T, Harada K, Matsumura T, Tukiyama T (2004) Oriental medicinal herb, Periploca sepium, extract inhibits growth and IL-6 production of human synovial fibroblast-like cells. Pharm Bull 27:1691-1693

Toshio F, Kazue S, Taro N (2003) Preliminary evaluation of anti nephritis and radical scavenging activities of glabridin from Glycyrrhiza glabra Linn. Fitotherapia 74:624-629

Tsuda T, Kubota K, Yasuda K, Nishikava S, Sugaya A, Sugaya E (1986) Effects of Chinese herbal medicine "Kanbalu-Taiso-To" on transmembrane ionic currents and its local anesthetic action. J Ethnopharmacol 17(3):257-261

Van Marle J, Aarsen PN, Lind A, van Weeren Kramer J (1981) Deglycyrrhizinised liquorice (DGL) and the renewal of rat stomach epithelium. Eur J Pharmacol 72:219-225

Van Rossum TG, Vulto AG, Hop WC, Schalm SW (1999) Pharmacokinetics of intravenous glycyrrhizin after single and multiple doses in patients with chronic hepatitis $\mathrm{C}$ infection. Clin Ther 21:2080-2090

Van Rossum TG, Vulto AG, Hop WC, Schalm SW (2001) Glycyrrhizin-induced reduction of ALT in European patients with chronic hepatitis C. Am J Gastroenterol 96:2432-2437

Varsha S, Agrawal RC, Sonam P (2013) Phytochemical screening and determination of antibacterial and anti-oxidant potential of Glycyrrhiza glabra root extracts. J Environ Res Dev 7(4):1552-1558

Vashist H, Sharma D (2013) Pharmacognostical aspects of Glycyrrhiza glabra. Asian J Pharm Clin Res 6(4):55-59

Vaya J, Belinky PA, Aviram M (1997) Antioxidant constituents from licorice roots: isolation, structure elucidation and antioxidative capacity toward LDL oxidation. Free Radic Biol Med 23:302-313

Vaya J, Belinky PA, Aviram M (1998) Structural aspects of the inhibitory effect of glabridin on LDL oxidation. Free Radic Biol Med 24:1419-1429

Vibha JB, Choudhary K, Singh M, Rathore MS, Shekhawat NS (2009) A Study on pharmacokinetics and therapeutic efficacy of Glycyrrhiza glabra: a miracle medicinal herb. Bot Res Int 2(3):157-163 
Wang ZY, Athar M, Bickers DR (2000) Licorice in foods and herbal drugs: chemistry, pharmacology, toxicology and uses. In: Mazza G, Oomah BD (eds) Herbs, botanicals and teas. Technomic Publishing Co., Lancaster, PA, pp 321-335

Wang W, Hu X, Zhao Z, Liu P, Hu Y, Zhou J, Zhou D, Wang Z, Guo D, Guo H (2008) Antidepressantlike effects of liquiritin and isoliquiritin from Glycyrrhiza uralensis in the forced swimming test and tail suspension test in mice. Prog Neuropsychopharmacol Biol Psychiatry 32:1179-1184

Weiss RF, Fintelmann V (2000) Herbal medicine. Georg Thieme Verlag, Stuttgart

Williamson EM (2003) Potter's cyclopedia of herbal medicine. C.W. Daniel, Saffron Walden, pp 269-271

Won SR, Kim SK, Kim YM, Lee PH, Ryu JH, Kim JW, Rhee HI (2007) Licochalcone A: a lipase inhibitor from the roots of Glycyrrhiza uralensis. Food Res Int 40:1046-1050

Wu YT, Shen C, Yin J, Yu JP, Meng Q (2006) Azathioprine hepatotoxicity and the protective effect of liquorice and glycyrrhizic acid. Phytother Res 20(8):640-645

Xing GX, Li N, Wang T, Yang MY (2003) Advances in studies on flavonoids of licorice. China J Chin Mater Med 28(7):593-597

Yamamura Y, Kawakami J, Santa T, Kotaki H, Uchino K, Sawada Y, Tanaka N, Iga T (1992) Pharmacokinetic profile of glycyrrhizin in healthy volunteers by a new high-performance liquid chromatographic method. J Pharm Sci 81(10):1042-1046

Yoon G, Jung YD, Cheon SH (2005) Cytotoxic allylretrochalcone from the roots of Glycyrrhiza inflate. Chem Pharm Bull 53:694-695

Zhang Q, Ye M (2009) Chemical analysis of the Chinese herbal medicine Gan-Cao (licorice). J Chromatogr 1216(11):1954-1969

Zhao ZY, Wang WX, Guo HZ, Guan ZQ, Zhou DF (2006) Anti-depressive effect of liquiritin on chronic stress depression in rats. Chin J Clin Rehabil 27:69-72

Zhu YP (1998) Chinese materia medica: chemistry, pharmacology and applications. Harwood Academic Publishers, Amsterdam

Zhu S, Sugiyama R, Batkhuu J, Sanchir C, Zou K, Komatsu K (2008) Survey of Glycyrrhizae Radix resources in Mongolia: chemical assessment of the underground part of Glycyrrhiza uralensis and comparison with Chinese Glycyrrhizae Radix. Phytother Res 22(2):141-148 